\title{
Histone 4 lysine 8 acetylation regulates proliferation and host-pathogen interaction in Plasmodium falciparum
}

\author{
Archana P. Gupta, Lei Zhu, Jaishree Tripathi, Michal Kucharski, Alok Patra and Zbynek Bozdech*
}

\begin{abstract}
Background: The dynamics of histone modifications in Plasmodium falciparum indicates the existence of unique mechanisms that link epigenetic factors with transcription. Here, we studied the impact of acetylated histone code on transcriptional regulation during the intraerythrocytic developmental cycle (IDC) of P. falciparum.

Results: Using a dominant-negative transgenic approach, we showed that acetylations of histone $\mathrm{H} 4$ play a direct role in transcription. Specifically, these histone modifications mediate an inverse transcriptional relationship between the factors of cell proliferation and host-parasite interaction. Out of the four $\mathrm{H} 4$ acetylations, H4K8ac is likely the ratelimiting, regulatory step, which modulates the overall dynamics of $\mathrm{H} 4$ posttranslational modifications. H4K8ac exhibits maximum responsiveness to HDAC inhibitors and has a highly dynamic distribution pattern along the genome of $P$. falciparum during the IDC. Moreover, H4K8ac functions mainly in the euchromatin where its occupancy shifts from intergenic regions located upstream of $5^{\prime}$ end of open reading frame into the protein coding regions. This shift is directly or indirectly associated with transcriptional activities at the corresponding genes. H4K8ac is also active in the heterochromatin where it stimulates expression of the main antigenic gene family (var) by its presence in the promoter region.
\end{abstract}

Conclusions: Overall, we demonstrate that $\mathrm{H} 4 \mathrm{~K} 8 \mathrm{ac}$ is a potential major regulator of chromatin-linked transcriptional changes during $P$. falciparum life cycle which is associated not only with euchromatin but also with heterochromatin environment. This is potentially a highly significant finding that suggests a regulatory connection between growth and parasite-host interaction both of which play a major role in malaria parasite virulence.

Keywords: P. falciparum, H4K8ac, Chromatin, Transcriptional dynamics, HDAC inhibitors, ChIP-Seq

\section{Background}

Plasmodium falciparum, one of the protozoan parasites responsible for malaria in humans, exhibits coordinated mechanisms of transcriptional regulation during the development through its life cycle. There is mounting evidence that epigenetic mechanisms contribute to this unique gene regulation and thus are vital for the parasite's growth and development [1-10]. Besides, absence of the linker histone $\mathrm{H} 1$ [11], scarcity of transcription factors [12] and lack of a functional RNA interference system [13] has led to a working model in which

*Correspondence: zbozdech@ntu.edu.sg

School of Biological Sciences, Nanyang Technological University, 60 Nanyang Drive, Singapore 637551, Singapore histone posttranslational modifications (PTMs) play a pivotal role in $P$. falciparum gene regulation. Based on this model, Plasmodium epigenome is considered mainly euchromatic [14-16], marked by unique combinations of histone variants and their posttranslational modifications (PTMs) [11, 17-19]. The abundance of parasite specific histone modifications is suggestive of the role of epigenetic mechanisms regulating parasite virulence $[18,19]$. Intriguingly, the genome-wide distribution of histone variants and their PTMs is highly dynamic across the $P$. falciparum intraerythrocytic developmental cycle (IDC) [20-23]. Like mRNA abundance, occupancy of many histone marks such as H4K8ac and H3K9ac shows single peak profiles across the IDC in a large proportion of 
the $P$. falciparum genes [21]. On the other hand, there are histone PTMs whose occupancy is constant throughout the IDC. These include canonical heterochromatin markers such as $\mathrm{H} 3 \mathrm{~K} 9 \mathrm{me} 3$ and $\mathrm{H} 3 \mathrm{~K} 36 \mathrm{me}$, implicated in gene silencing $[14,24,25]$ and few euchromatin histone marks such as H4K5ac and H3K14ac, either abundantly spread through the majority of the genome or confined to a small number of genomic loci [21]. Occupancy of histone variants also contributes to the dynamic chromatin remodeling throughout the $P$. falciparum IDC with some variants which associate with actively transcribed genes, while others play roles in chromatin structure [20, 2628]. Chromatin remodeling is also affected by dynamic nucleosome structures [29-33] and chromatin binding proteins [34-37] in P. falciparum. Likewise, the dynamics is reflected in occupancy of RNA polymerase II exhibiting distinct patterns for early and late expressed genes [38]. Altogether these findings suggest that the time component of the occupancy profiles across the IDC is one of the variables of the overall "histone code" playing a key fundamental role in gene expression during the Plasmodium life cycle.

Studying 13 canonical PTMs of H4 and H3, we have previously shown that acetylation of $\mathrm{H} 4$ at lysine residue 8 (H4K8ac) is among the most dynamic modifications occupying predominantly the $5^{\prime}$ intergenic regions ( $5^{\prime}$ IGRs) and $5^{\prime}$ termini of the open reading frames (ORFs) of more than half of the P. falciparum genes [21]. The single peak occupancy profiles of the $5^{\prime}$ IGR/ ORF-bound H4K8ac showed good correlation with the respective mRNA profiles across the IDC. This was highly surprising given that the "neighboring" PTMs at the H4 "tail" (H4K5ac and H4K12ac) exhibited a highly abundant but constant occupancy throughout the vast majority of the genome. Treatment of $P$. falciparum parasites with the Class I and II histone deacetylase (HDAC) inhibitor apicidin resulted in induction of the overall protein levels of $\mathrm{H} 4 \mathrm{~K} 8 \mathrm{ac}$ as well as its occupancy across the genome [39]. H4K8ac (together with $\mathrm{H} 3 \mathrm{~K} 9 \mathrm{ac}$ ) was also found to be an effector of the DNA damage stress response, being induced by treatment of $P$. falciparum parasites with methyl methanesulfonate (MMS) at multiple stages of the IDC [40]. The MMS-induced levels of H4K8ac in P. falciparum coincide with transcriptional induction of stress responses. Intriguingly, artemisinin, the main chemotherapeutics for malaria treatment, solicited a similar effect characterized by increased levels of H4K8ac and upregulation of the stress response genes [40]. This strongly suggests that H4K8ac plays a role in transcription regulation associated with both, progression of the Plasmodium life cycle, and, responses to external perturbations/stresses. Surprisingly, in other eukaryotic organisms, $\mathrm{H} 4 \mathrm{~K} 8 \mathrm{ac}$ is yet to be implicated in any major processes of epigenetic regulation of gene expression. In yeast and humans, H4K8ac seems to play an auxiliary role in transcription, being a part of an overall euchromatin-linked histone PTM complex that occupies active promoters [41, 42]. This may suggest that in contrast to most eukaryotes, during the Plasmodium evolution, H4K8ac acquired new functions in epigenetic regulation of gene expression and possibly emerged as one of the most crucial histone marks.

All above-mentioned studies, however, provided only associative evidence of H4K8ac involvement in transcription showing modest albeit statistically significant overlaps between H4K8ac-bound genetic loci and transcriptionally deregulated genes [21, 39, 40]. Here, we wanted to establish direct links between H4K8ac and transcription, and evaluate these in context of the neighboring H4 PTMs (H4K5ac, H4K12ac and H4K16ac) detected in $P$. falciparum. For this, we suppressed the studied acetylations in P. falciparum cell lines that (over) expressed $\mathrm{H} 4$ genes with mutations at lysines 5, 8, 12, 16. The hypoacetylation of histone $\mathrm{H} 4$ resulted in broad transcriptional changes characterized by upregulation of genes involved in cell proliferation and downregulation of genes of host-parasite interactions and antigenic presentation/variation. Accordingly, there was an increase in multiplication rate of $P$. falciparum parasites when $\mathrm{H} 4 \mathrm{~K} 8 \mathrm{ac}$ or all $4 \mathrm{H} 4$ acetylations were suppressed. On the other hand, H4K8 exhibited maximum level of hyperacetylation induced by HDAC inhibitors compared to all other euchromatin marks; however, this hyperacetylation is highly transient. ChIP-Seq results showed that H4K8ac shifts its position back-and-forth between the $5^{\prime}$ IGRs in the early and late IDC stages to the $5^{\prime} \mathrm{ORF}$ in the middle IDC stage. Besides its euchromatin-linked roles, H4K8ac also functions in the context of heterochromatin where it is involved in activation of the major antigenic variation gene family (var).

\section{Results \\ Dominant-negative transgenic lines for $\mathrm{H} 4$ acetylations}

In the first step, we created dominant-negative P. falciparum transgenic parasite lines transfected with $\mathrm{pBcamR}$ plasmid containing HA-tagged $\mathrm{H} 4$ genes in which the targeted lysine (K) residues (K5, K8, K12, K16) where replaced with arginine (R) (Additional file 1). In total, we generated five transgenic lines with the individual mutations (H4K5R, H4K8R, H4K12R, H4K16R) or with all 4 lysines changed to arginine (H4ac4R) and two additional control lines with either HA-tag only (HA) or wild-type HA-tagged $\mathrm{H} 4$ gene (H4-HA). As expected, there was an increase in the plasmid copy number and expression of the transgenic $\mathrm{H} 4$ proteins in $P$. falciparum grown in $10 \mu \mathrm{g} / \mathrm{ml}$ of blasticidin compared to $2.5 \mu \mathrm{g} / \mathrm{ml}$ in all 
parasite lines (Additional file 2: Figure S1a and Fig. 1a, respectively). Cell lysate fractionation showed that the transgenic $\mathrm{H} 4$ proteins could be solubilized only by high salt extraction of the nuclear fraction (Fig. 1b). More importantly, the intensities of HA-tagged $\mathrm{H} 4$ proteins were found to be, 3.12-fold higher for H4K8R, 2.6-fold higher for H4K12R and 3.6-fold higher for H4K16R compared to endogenous $\mathrm{H} 4$ protein in the transfectants at $10 \mu \mathrm{g} / \mathrm{ml}$ of blasticidin (Fig. 1a and Additional file 2: Figure S1h). This indicates partial but significantly higher displacement of endogenous proteins by the HA-tagged $\mathrm{H} 4$ protein. Transgenic proteins were also detected in the acid-extracted histone fractions and immuno-fluorescence microscopy of H4 K8R confirmed its nuclear localization (Additional file 2: Figure S1b). Taken together, these results demonstrate that the episomally expressed $\mathrm{H} 4$ proteins are targeted to the $P$. falciparum nucleosomes, presumably displacing the endogenous $\mathrm{H} 4$ protein and by that suppressing the respective acetylations. Hence, these transgenic lines provide an experimental tool to investigate the role of $\mathrm{H} 4$ lysine residues in epigenetic regulation of gene expression during $P$. falciparum IDC.

\section{Functional implication of the dominant-negative inhibition of $\mathrm{H} 4$}

Next, we carried out transcriptome analyses of the transfectants grown in the presence of $10 \mu \mathrm{g} / \mathrm{ml}$ of blasticidin. By comparing the transcriptional profiles of the $\mathrm{H} 4 \mathrm{~K} / \mathrm{R}$ mutants with those from both controls at three stages of the IDC, we observed broad transcriptional changes (Fig. 1c). Remarkably, there appears to be strong similarities between the transcriptional changes induced by the dominant-negative effect of all five H4K/R mutants. Overall, there were higher number of genes that were differentially expressed in the ring and schizont compared to the trophozoite stages. The transcription patterns of the dominant-negative transfectants was not or negatively correlated to $\mathrm{HA}$ and positively correlated to each other when normalized to H4-HA (Additional file 2: Figure S1c). On the other hand, there were essentially no transcriptional changes between the unmutated $\mathrm{H} 4-\mathrm{HA}$ and transfectant with the empty vector (HA) also grown at $10 \mu \mathrm{g} / \mathrm{ml}$ of blasticidin (Additional file 2: Figure S1d). Altogether, these results indicate that the acetylations at the 4 lysine residues of $\mathrm{H} 4$ act in a similar way possibly reflecting a synergistic and/or complimentary function in transcription during the P. falciparum IDC. Nonetheless, there were subtle differences within the individual profiles with H4ac4R clustering closer with H4K8R in the ring and trophozoite stages (Pearson's correlation coefficient 0.75 and 0.71 , respectively) compared to the other 3 mutants (Fig. 1c; Additional file 2: Figure S1c). Given that
H4ac4R shows consistently the strongest effect on transcription, this may suggest a key role of $\mathrm{H} 4 \mathrm{~K} 8 \mathrm{ac}$ in this process.

Functional analyses of the induced transcriptional changes showed a high consistency in the altered mRNA levels for all enriched pathways for all four $\mathrm{H} 4$ acetylations (Fig. 1d; Additional file 3: Table S1, Additional file 4: Figure S2). Moreover, similar pathways were deregulated in the H4K8R transfectant at the schizont stage when the blasticidin concentration was increased from 2.5 to $10 \mu \mathrm{g} /$ $\mathrm{ml}$ whereas H4-HA grown at 2.5 and $10 \mu \mathrm{g} / \mathrm{ml}$ of blasticidin induced very few transcriptional changes (Additional file 2: Figure S1e), confirming that the transcriptional deregulation is a direct result of dominant-negative expression of the mutated $\mathrm{H} 4$ protein. Namely, the overexpression of the $\mathrm{H} 4$ mutants caused upregulation of a wide range of genes involved in cellular pathways associated with growth and replication (e.g., proliferation) of $P$. falciparum during the IDC. These include genes encoding factors of the assembly of cytoplasmic and the organellar ribosomes, glycolysis, DNA replication and nuclear encoded genes for apicoplast and mitochondrial protein transport (annotated by MPMP; http://mpmp.huji.ac.il/) (Fig. 1d). In addition, there was an upregulation of two classes of stress response pathways including the $D N A$ repair machinery and thioredoxin metabolism. While some pathways (such as DNA repair) were upregulated throughout the IDC, others were typically de-repressed during their transcriptional downturn. For example, the genes coding for $40 \mathrm{~S}, 50 \mathrm{~S}$ and $60 \mathrm{~S}$ cytoplasmic ribosomal proteins normally expressed during rings [43] were upregulated in the trophozoite and schizont stages, whereas genes encoding for mitochondrial and apicoplast ribosomal proteins normally expressed in the schizonts were upregulated in the rings (Additional file 2: Figure S1f). This indicates that $\mathrm{H} 4$ acetylations facilitate transcriptional suppression of proliferation related genes in a life cycle-specific manner, hence regulating the growth of parasite. This occurs in all three major developmental stages of the IDC in which the transgenic histones were expressed at the protein levels (Additional file 2: Figure S1g). Interestingly, the disruptions of H4K8ac or the 4 acetylations lead to significant increases in the parasite multiplication rate (MR) by up to 1.3-fold and twofold, respectively (Fig. 1e). This is most likely a direct result of the induced levels of the mutated $\mathrm{H} 4$ proteins as no alterations in MR were observed at $2.5 \mu \mathrm{g} / \mathrm{ml}$ of blasticidin in all transfectant parasites lines. Surprisingly, this was not associated with an increased number of newly formed merozoites in the segmented schizonts measured by light microscopy (Fig. 1f). Moreover, both the mutant and non-mutant transfectants have an identical length of the IDC, measured by transcriptomics analysis (Additional 


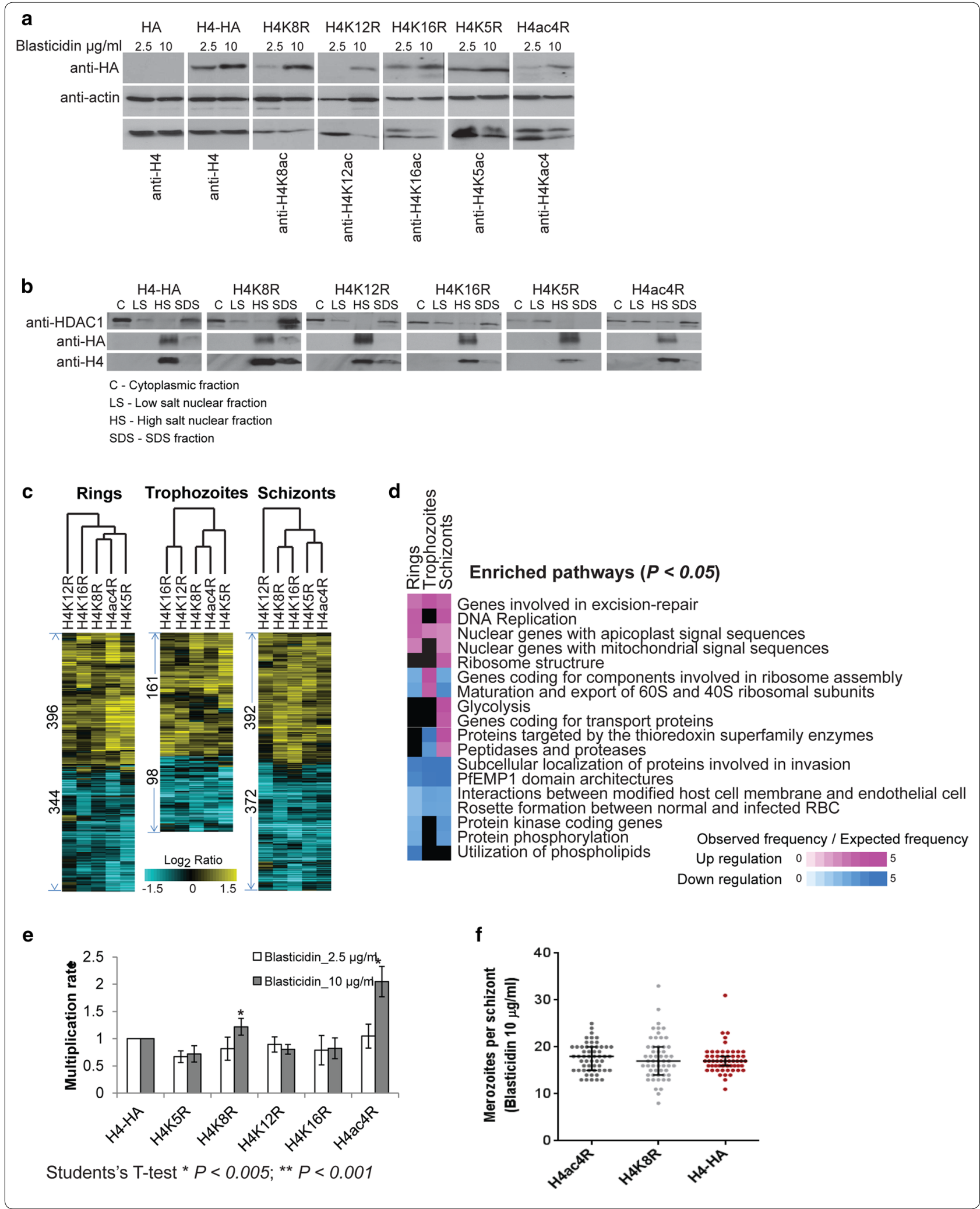


(See figure on previous page.)

Fig. 1 Histone $\mathrm{H} 4$ acetylation mutants. a Western blot analysis using total protein from the transfectants grown at $2.5 \mathrm{and} 10 \mu \mathrm{g} / \mathrm{ml} \mathrm{blasticidin}$ to check the presence of HA-tagged $\mathrm{H} 4$ proteins using antibodies against HA. Histone antibodies were used as positive control to confirm the expression of endogenous histones and actin was used as a loading control. b Western blot analysis carried out from cytoplasmic, low salt nuclear, high salt nuclear and total SDS fractions to confirm nuclear localization of HA-tagged H4 proteins in the transfectants. c Microarray expression analysis for transfectants grown at $10 \mu \mathrm{g} / \mathrm{ml}$ blasticidin. Heat maps represent the differentially expressed genes in the transfectants at each stage (Student's $t$ test, $P<0.05$ ). Data shown is $\log _{2}$ ratio of average of biological triplicates, normalized to H4-HA transfectant. d Functional pathways significantly up or downregulated in the differentially expressed gene sets (data from $\mathbf{c}$ ) of the transfectants. The scale shows the fold enrichment of number of genes in the specific pathways [based on hypergeometric test $(P<0.05)$ ]. e Effect of $\mathrm{H} 4$ mutations on multiplication. Cells were grown in $2.5 \mathrm{or} 10 \mu \mathrm{g} / \mathrm{ml}$ blasticidin and FACS using Hoechst stain was carried out to count the number of new rings at each invasion cycle for 6 cycles. $\mathbf{f}$ The scatter plot of merozoite number in the segmented schizonts in H4ac4R, H4K8R and H4-HA transfectants determined by Giemsa stain light microscopy

file 5: Table S5). This suggests that the increased MR is likely facilitated by a higher fraction of viable merozoite with elevated levels of infectivity. It will be interesting to explore this possibility in future studies.

The most predominant functional groups enriched among the downregulated genes were factors of hostparasite interactions annotated as PfEMP1 domain architecture, rosette formation between normal and infected $R B C$ and interactions between modified host cell membrane and endothelial cells (Fig. 1d). In particular, we observed downregulation of essentially all members of two gene families implicated in antigenic variation and immune evasion, var and rifin. The other important downregulated pathway consisted of genes involved in merozoite invasion, which includes merozoite surface proteins, rhoptry associated proteins, reticulocyte binding protein homologs and erythrocyte binding antigens (Additional file 3: Table S1). In contrast, downregulation of these genes was independent of the developmental stage, typically occurring throughout the IDC (Fig. 1d; Additional file 4: Figure S2). We validated that the 40S and $50 \mathrm{~S}$ cytoplasmic ribosomal proteins were upregulated by, 1.7 to 2 -fold, and, 1.7- to 4.3-fold, in trophozoite and schizont stages, respectively. On the other hand, invasion-related genes, RAP2 and RAP3, and, MSP and RAP3, were confirmed to be downregulated showing a fold change of $<1$ compared to wild-type parasites in trophozoite and schizont stages, respectively (Additional file 2: Figure S1i). Taken together, these results suggest that the 4 lysine residues of the $\mathrm{H} 4$ tail play a central role in regulating several key biological functionalities by which the parasite adapts to its environment. Specifically, the $\mathrm{H} 4$ acetylations facilitate an inverse regulatory relationship between growth and multiplication on one-side and host-parasite interactions on the other.

\section{H4K8ac is the dynamic component of the $\mathrm{H} 4$ tetra-acetylation moiety}

Next, we wished to compare the responsiveness of the four $\mathrm{H} 4$ lysine acetylations to HDAC inhibition in a broader context of $P$. falciparum chromatin remodeling
[21, 39, 40]. Highly synchronized trophozoites were treated with $\mathrm{IC}_{90}$ concentrations of Trichostatin A (TSA) or apicidin (50 and $70 \mathrm{nM}$, respectively) for $6 \mathrm{~h}$ followed by removal of the drug and culturing for another 2,4 and $6 \mathrm{~h}$, similar to our previous study [44]. Out of the $4 \mathrm{H} 4$ acetylations, H4K8ac and (to a lesser degree) H4K16ac responded to both HDAC inhibitors, while H4K5 and H4K12 acetylation levels were unchanged (Fig. 2a). Both HDAC inhibitors induced acetylation at other euchromatin marks including H3K23ac, H3K56ac and to lesser degree H3K9ac whereas euchromatin-linked (tri)methylations of H3K4 and H4K20 were unresponsive. Finally, there was a dramatic increase in the signal intensity using an antibody against $\mathrm{H} 4$ tetra-acetylation (H4ac4). This likely corresponds to the changes mainly at H4K8ac and (less so) H4K16ac, given that the levels of H4K5ac and H4K12ac appear to be constitutive. As mentioned above, $\mathrm{H} 4 \mathrm{~K} 8 \mathrm{ac}$ is the most dynamic euchromatin mark whose occupancy is tightly correlated with transcriptional activity, while H4K16ac showed only moderate-to-low levels of occupancy changes and is virtually uncoupled from transcription [21]. This suggests that out of the two dynamic $\mathrm{H} 4$ acetylations, $\mathrm{H} 4 \mathrm{~K} 8 \mathrm{ac}$ may play a pivotal role in regulation of gene expression that is ultimately mediated by the H4ac4 epigenetic moiety. Hence, in the following parts of our study, we focus on H4K8ac as a major regulatory factor in gene expression during the $P$. falciparum IDC.

The effect of both TSA and apicidin on all the responsive histone acetylations appears to be transient as most of the histone modifications returned to their basal levels over $6 \mathrm{~h}$ after the compound removal (Fig. 2a). This is consistent with our previous study showing a transient effect of HDAC inhibitors on P. falciparum transcriptome [44]. To explore this phenomenon further, we carried out a "treatment/wash-off" time course experiment where the highly synchronized trophozoites were first exposed to $50 \mathrm{nM}$ of TSA and subsequently samples were collected $0,0.5,2$ and $4 \mathrm{~h}$ after the drug removal (Fig. 2b). These samples were used for transcriptomic and ChIP-on-chip analysis of H4K8ac occupancy, 


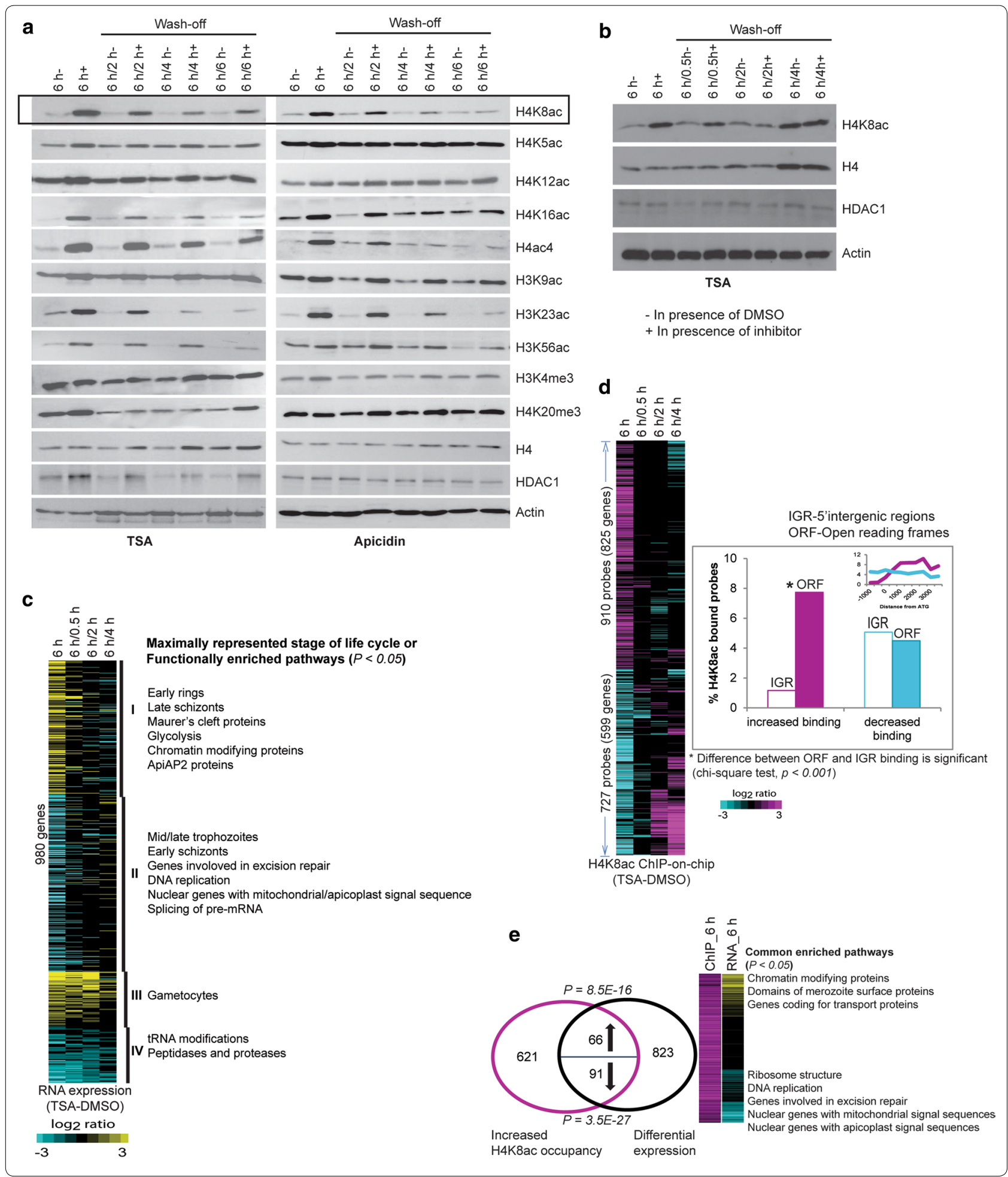


(See figure on previous page.)

Fig. 2 Effect of HDAC inhibitors on P. falciparum. a Western blot analysis to check the effect of HDAC inhibitors on histone modifications. Trophozoite stage parasites were cultured for $6 \mathrm{~h}$ with DMSO $(6 \mathrm{~h}-), 70 \mathrm{nM}$ of Trichostatin A (TSA) or $75 \mathrm{nM}$ of Apicidin ( $6 \mathrm{~h}+$ ). The drug was subsequently washed off, and the cells were grown for another $2 \mathrm{~h}(6 \mathrm{~h} / 2 \mathrm{~h}), 4 \mathrm{~h}(6 \mathrm{~h} / 4 \mathrm{~h})$ or $6 \mathrm{~h}(6 \mathrm{~h} / 6 \mathrm{~h})$. The antibodies used for each blot are shown on the right. b Similar experiment was repeated with TSA treatment for $6 \mathrm{~h}$, subsequent wash off and growth for $0.5 \mathrm{~h}(6 \mathrm{~h} / 0.5 \mathrm{~h}), 2 \mathrm{~h}(6 \mathrm{~h} / 2 \mathrm{~h})$ and $4 \mathrm{~h}(6 \mathrm{~h} / 4 \mathrm{~h})$. Total protein was extracted from the respective samples for western blot analysis using antibodies against histone $\mathrm{H} 4$ or $\mathrm{H} 4 \mathrm{~K} 8 \mathrm{ac}$ or Pf HDAC1. c Microarray expression analysis of TSA treated cells. TSA or DMSO treatment for $6 \mathrm{~h}$ was done in biological triplicates and subsequent wash-off experiments were done in duplicates. The heat map (left panel) shows average $\log _{2}$ ratios of replicates (TSA minus DMSO) of the genes differentially expressed after $6 \mathrm{~h}$ TSA exposure (Student's $t$ test, $P<0.05$ ). Right panel represents the parasite stage whose genes are maximally expressed as well as the functionally enriched MPM pathways in each of the clusters. $\mathbf{d}$ ChIP-on-chip using H4K8ac antibody to assess differential binding upon TSA treatment. All experiments were done in at least duplicates. The heat map on the left shows average $\log _{2}$ ratios of replicates (TSA minus DMSO) of the probes differentially acetylated after 6 -h TSA exposure (Wilcoxon rank sum test, $P<0.05$ ). Graph on the right shows the percentage of probes that are differentially acetylated upon TSA treatment for $6 \mathrm{~h}$. Inset graph shows the differential occupancy across the gene body. Venn diagram represents the overlap between differential expression and increased H4K8 occupancy in the ORFs due to TSA. Binomial distribution was used to assign $P$ values for up or downregulated genes overlapping with H4K8ac hyperacetylation. Heat map on the right represents the fold change in H4K8ac occupancy or RNA expression of the hyperacetylated genes. Functional pathways (MPM) significantly enriched in the up-or downregulated gene sets are shown

simultaneously. In this experimental setting, TSA caused a dramatic deregulation of the IDC transcriptional cascade with a broad downregulation of trophozoite-specific genes and upregulation of genes normally expressed in other stages (early ring and early schizonts) (Fig. 2c). This deregulation is largely reversible such that even 30 min after the drug removal, the majority of the transcripts returned to their original levels. However, there were two gene clusters whose TSA-induced transcriptional change was stable for at least $2 \mathrm{~h}$. These include genes of gametocyte and merozoite stages among the upregulated and tRNA modifications and peptidases and proteases among the downregulated genes (Fig. 2c; Additional file 6: Table S2). In future studies, it will be interesting to understand the molecular mechanisms that underline both the reversible and irreversible transcriptional changes induced by the HDAC inhibitors. The chromosomal occupancy of H4K8ac appeared also highly sensitive to TSA at least 1637 genetic loci corresponding to 1424 genes (Fig. 2d). There is a remarkable asymmetry in the distribution of the TSA-induced H4K8ac occupancy that is significantly enriched within the ORFs $(P<0.001)$ compared to the $5^{\prime}$ IGRs (Fig. 2d inset). There was a modest but significant overlap between the TSA-induced acetylation and altered transcription. The increased H4K8ac within the ORFs coincided with increased expression of 66 genes (hypergeometric test, $P=8.5 \mathrm{E}-16)$ and decreased expression of 91 genes (hypergeometric test, 3.5E-27) (Fig. 2e; Additional file 7: Table S3). The upregulated gene set is functionally enriched for several pathways such as chromatin modifying proteins and merozoite surface proteins and genes with maximum expression in gametocytes and merozoite stages. The downregulated gene set upon H4K8ac hyperacetylation included factors of DNA replication, excision repair and ribosome structure. This effect is opposite to the $\mathrm{H} 4$ hypoacetylation where genes of the proliferation pathways were upregulated, and merozoite surface proteins were downregulated (Fig. 1d). This further supports our model in which H4K8ac plays a central, regulatory role within the H4ac4 moiety.

\section{H4K8ac regulates gene expression within both euchromatin and heterochromatin}

Next, we wished to explore the distribution of the H4K8R mutant protein within the $P$. falciparum chromatin and correlate these to the induced transcriptional changes to find key regions of its epigenetic activity. For this we compared ChIP-on-chip results from the mutant H4K8R and unmutated H4-HA using an anti-HA antibody (Fig. 3a). Here, we observed variable occupancy patterns across the $P$. falciparum chromosomes, which suggests of the transgenic histones, displaced the endogenous histones partially with some regions being fully protected while others tolerating the mutant histone to a higher degree. Overall, there was a significant skew of the H4K8R binding to the 5'IGRs in rings and trophozoites while in schizonts, the H4K8R and H4-HA exhibit a more similar distribution. This is in sharp contrast to the TSA-induced hyperacetylation that occurs almost exclusively at the ORF of the genes (see Fig. 2d). Moreover, we observed that the increased (hypoacetylation driving) occupancy of H4K8R coincided significantly with differential expression including both up and downregulated genes. The upregulated gene set was enriched for nuclear encoded genes responsible for apicoplast/mitochondrial import, DNA replication and repair machinery. On the other hand, the downregulated genes with enhanced H4K8R occupancy included genes encoding the two main subtelomeric gene families involved in antigenic variations (var and rifin). This is particularly evident to the var genes where the enhanced H4K8R occupancy 


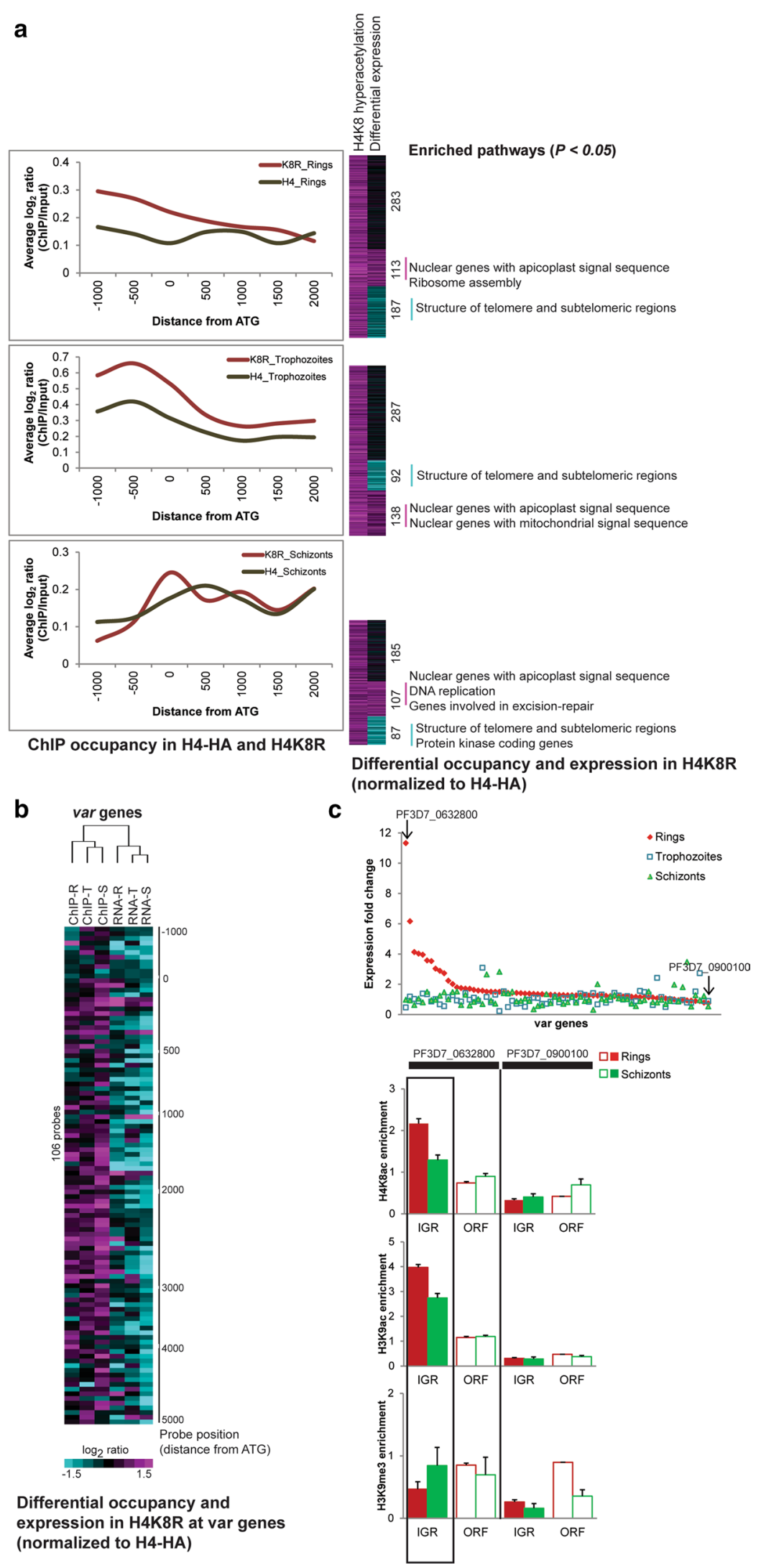


(See figure on previous page.)

Fig. 3 Euchromatin- and heterochromatin-linked H4K8ac. a ChIP-on-chip for H4-HA and H4K8R transfectants using anti-HA antibody. All microarrays were done in triplicates, and differential binding was assessed by Wilcoxon rank sum test $(P<0.05)$. Graphs on the left show average ChIP/Input $\log _{2}$ ratio of all the probes binned according to their distance from the start codon. Heat maps on right depict the probes with increased binding and change in expression in the corresponding genes in H4K8R transfectants (compared to H4-HA). Functional pathways (MPMP) significantly enriched in the up or downregulated gene sets are shown. b Analysis of var genes linked heterochromatin in H4K8R. Heat map represents the differential binding at var gene loci and differential RNA expression of corresponding genes (H4K8R normalized to H4-HA transfectants). The distance from ATG marked on the right depicts the microarray probe position with respect to gene start. c Histone marks at active/inactive var gene in 3D7 clone. Graph on top represents microarray gene expression values of var genes in one of the $3 \mathrm{~d} 7 \mathrm{clones}$. The highest and least expressed var genes are marked with the arrow. The lower 3 graphs show the ChIP enrichment by QPCR of the most dominantly expressed var gene and the least expressed var gene (input subtracted Ct values normalized to ORF of PF3D7_1240300). Primers were designed within $1000 \mathrm{bp}$ on each side of the gene start. The results of the other 3 clones are shown in Additional file 4: Figure S3

coincides with dramatically decreased transcript levels in all three stages of the IDC (Fig. 3b). This implies that the H4K8R-driven hypoacetylation at the var ORFs suppresses their transcription. This is surprising given that the subtelomeric regions of the P. falciparum chromosomes are in the heterochromatin state associated with typical heterochromatin factors such as H3K9me3 and heterochromatin binding protein HP1 $[15,35]$. Our result suggests that $\mathrm{H} 4 \mathrm{~K} 8 \mathrm{ac}$, one of the main euchromatin markers in P. falciparum, also contributes to var gene regulation.

Given that the ChIp-on-chip measurements (Fig. 3b) were carried out with a parasite culture that were not selected for a single var gene expression, it was impossible to discern if the detected H4K8ac effect occurs specifically at the dominant transcript or all var genes. To distinguish between these two possibilities, we examined several isogenic clones derived by serial dilution of an in vitro culture of the P. falciparum 3D7 strain that exhibit a single var gene expression. These clones reflect the mutually exclusive expression with a single dominant transcript expressed at significantly higher levels in the ring stage, compared to the rest of the family (Fig. 3c; Additional file 8: Figure S3a). Using chromatin immunoprecipitation, we show that in 3 of the 4 clones, $\mathrm{H} 4 \mathrm{~K} 8 \mathrm{ac}$ along with $\mathrm{H} 3 \mathrm{~K} 9 \mathrm{ac}$, is over-enriched at the intergenic region of the dominant var gene in the ring stage (Fig. 3c; Additional file 8: Figure S3b). On the other hand, H3K9me3 was enriched in the intergenic region of the dominant var transcript during the schizont stage, while in the ring stage this modification was mostly present in the ORF (Fig. 3c; Additional file 8: Figure S3b). Taken together, these results indicate that H4K8ac contributes to transcriptional regulation not only in euchromatin but also within a heterochromatin context. Consistent with its linking role between growth and host-parasite interaction (see above), this modification participates in induction (and possibly mutual expression) of the main antigenic factor in $P$. falciparum, the var gene family.

\section{Genome-wide acetylation of H4K8-bound DNA follows transcriptional dynamics during the IDC}

Next, we carried out chromatin immunoprecipitation (ChIP)-coupled high-throughput sequencing (ChIPSeq) throughout the $P$. falciparum IDC to investigate the chromosomal distribution of $\mathrm{H} 4 \mathrm{~K} 8 \mathrm{ac}$ with high resolution. H4K8ac-immunoprecipitated DNA from highly synchronized parasites at the ring (8-12 hpi), trophozoite (24-28 hpi) and schizont (34-38 hpi) stages was subjected to massively parallel sequencing to obtain an average genome coverage ranging from 18-29X and 296-476X using MiSeq and HiSeq, respectively (Additional file 1). The normalized ChIP over input tag counts calculated for $2 \mathrm{~kb}$ region around the start codon (from $1 \mathrm{~kb}$ upstream to $1 \mathrm{~kb}$ downstream) of each gene showed correlation $>0.8$ between MiSeq and HiSeq runs (Additional file 9: Figure S4a). Figure 4a shows examples of read counts spread across 3 genes highly expressed in ring, trophozoite and schizont stage, respectively. A total of 4648, 6306 and 3515 peaks were obtained for the ring, trophozoite and schizont stage HiSeq samples, respectively (Fig. 4b; Additional file 10: Table S4). In all 3 IDC developmental stages, we could observe H4K8ac occupancy peaks that were fully within the ORF or $5^{\prime}$ IGRs, while others overlapped both. The identified H4K8ac occupancy peaks reside either within or in intergenic regions of 52, 92 and $68 \%$ genes in the ring, trophozoite and schizont stages, respectively (Fig. $4 \mathrm{~b}$ ). These results suggest that H4K8ac is predominant in the trophozoite stage where its occupancy peaks associate with the largest number of genes. There is a higher overall sequence coverage generated by the ChIP-Seq reads in the $5^{\prime}$ IGRs followed by the peaks overlapping both $5^{\prime}$ IGRs and ORFs and that followed by peaks exclusive to the ORFs (Fig. 4c). This is in good agreement with the previous ChIP-onchip results showing that the majority of $\mathrm{H} 4 \mathrm{~K} 8 \mathrm{ac}$ is associated with $5^{\prime}$ IGRs with lesser occupancy within ORF [21]. We confirm this by ChIP-on-chip measurements with the identical same samples used for the RNA-Seq and showed that H4K8ac exhibits the highest occupancy 
a

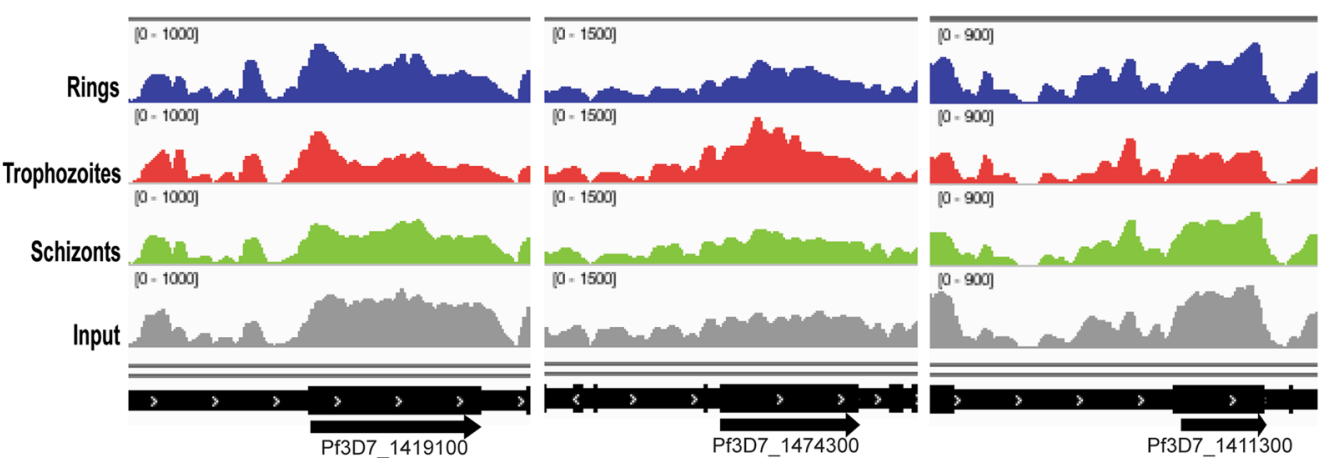

b
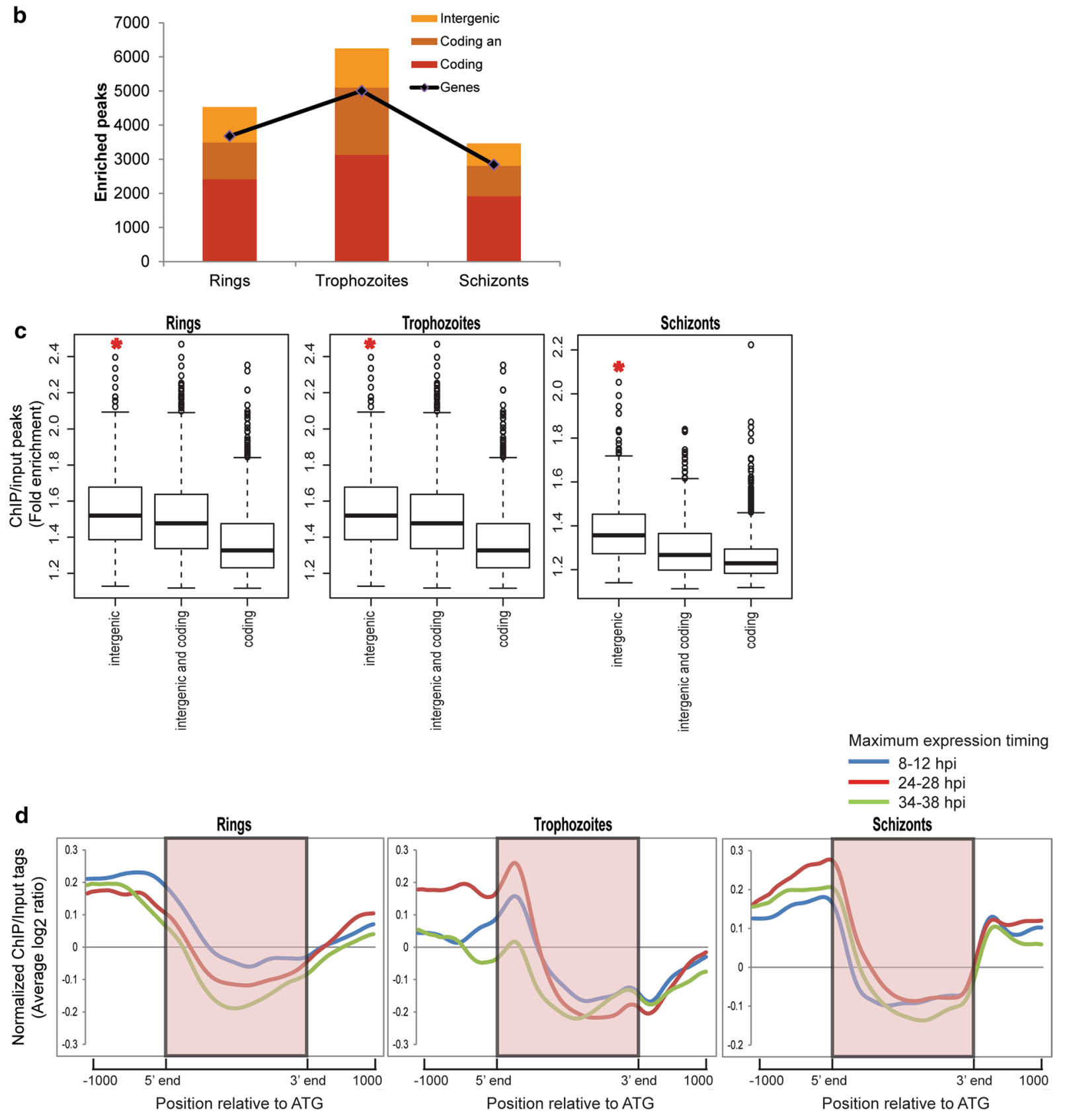
(See figure on previous page.)

Fig. 4 Genome-wide high-throughput ChIP-Seq to identify H4K8ac bound DNA. a A snapshot of the genome browser in Integrative Genomics Viewer showing normalized reads mapped to different regions of chromosome 14 representing one highly expressed gene region (highlighted) from each of the 3 stages. The graphs represent the chip over input ratios shown for gene Pf3D7_1419100, Pf3D7_1474300, Pf3D7_1411300 for rings (blue), trophozoites (red) and schizonts (green). Read coverage for input is shown in gray and the gene coordinate is marked in black. The tracks were normalized to library size such that the height of each track represents mapped read coverage. b Bar graph showing the number of H4K8ac peaks (identified by MACS using a $q$-value cut-off of $20 \%$ ). The line (graph) represents number of genes corresponding to the peaks. $\mathbf{c} B$ Box plots representing enrichment fold change of H4K8ac peaks covering intergenic regions, coding regions or both. The H4K8ac peaks and input peaks were normalized to the total number of reads and ratio of H4K8ac versus input peaks was calculated. *Denotes that IGR occupancy is significantly higher than ORF occupancy (Wilcoxon rank sum test, $P<1 \mathrm{e}-15$ ). $\mathbf{d}$ H4K8ac binding assessed by binning the total normalized read counts (ChIP-normalized read coverage/input-normalized read coverage) into equal number of bins covering 1000-bp upstream, the gene coding body and 1000-bp downstream of each gene. The resulting profiles are plotted for genes with maximum expression at 8-12, 24-28 and 34-38 hpi corresponding to the stage when the cells were harvested for immunoprecipitation

within 5'IGRs with the highest signal being detected in the trophozoite stage (Additional file 9: Figure S4b).

To evaluate this further, we analyzed the H4K8ac ChIPSeq results in the context of transcriptional stage-specificity for each gene (Fig. 4d). Indeed, in the first part of the IDC, the ring and trophozoite stages, H4K8ac showed maximum occupancy, predominantly at the $5^{\prime}$ IGRs $(1 \mathrm{~kb}$ upstream of the translational start) of transcriptionally active genes in both IDC stages, respectively. However, in schizonts, H4K8ac remains predominantly at the trophozoite-specific genes and increases at schizont genes only marginally. Strikingly, there is a significant shift in the positioning of H4K8ac along the gene structures throughout the IDC. In the ring stage, H4K8ac is mainly associated with relatively distal $5^{\prime}$ IGRs, while in the trophozoite stage, there is a narrow peak distributions at the translational start sites, skewed slightly toward the $5^{\prime}$ termini of the ORFs (Fig. 4d). In the schizont stage, H4K8ac appears to "retreat" back to the more distal $5^{\prime}$ IGRs, but a significant proportion of its occupancy still overlaps with the translational start sites. There is also a considerable rise in H4K8ac occupancy at the 3'IGRs in schizonts compared to the trophozoites (Fig. 4d, left two panels). Interestingly, in spite of the temporal shifts and the changing levels of the H4K8ac, the overall gene-based positional profiles of the H8K8ac were highly similar for all genes in each stage regardless of their transcriptional stage-specificity. Taken together, these results provide further evidence that H4K8ac is associated with transcriptional regulation of $P$. falciparum genes during the IDC, particularly regulating genes expressed during the mid-sections of the IDC, the trophozoite stage. At this stage, H4K8ac may contribute to transcriptional activation by repositioning its occupancy from $5^{\prime}$ IGRs into the 5 'termini of the ORFs.

\section{Discussion}

It is now clear that in $P$. falciparum, gene regulation, in some way, is responsive to the dynamic pattern of histone marks that undergoes multitude of changes through the asexual life cycle $[4,20]$. The unique plasticity of the distribution of histone marks during $P$. falciparum development is unseen in other eukaryotes. Here, we have demonstrated an important role for the histone $\mathrm{H} 4$ acetylations, especially at lysine 8 position, to be crucial in gene regulation in $P$. falciparum. It was previously shown that the activating histone marks are abundant and widely distributed in P. falciparum genome, but only some coincide with the transcriptional dynamics. However, $\mathrm{H} 4 \mathrm{~K} 8 \mathrm{ac}$ plays a unique role in $P$. falciparum biology that is distinct from H3K9ac and the other activating histone marks. Although all of them are marks of transcriptionally active euchromatin in P. falciparum, correlation of H4K8ac with RNA polymerase II occupancy [38] and response of H4K8ac to HDAC inhibitors and DNA damaging agents is unique $[39,40]$. The results presented here highlight the highly dynamic character of H4K8ac in the genome and provide first direct evidence about its importance for transcriptional reprogramming during the $P$. falciparum IDC. A certain threshold level of H4K8ac is likely required in both euchromatin and heterochromatin to allow the correct transcriptional regulation that employs both activating and suppressing factors. Here, we wish to argue that H4K8ac is the key dynamic component of the tetra-acetylation state of histone 4 (H4ac4) that ultimately functions as a main epigenetic effector, presumably via binding to trans-factors ("chromatin readers"). Although little is known about chromatin readers in P. falciparum, these may include proteins with conserved chromatin binding domains such as the bromodomain carrying proteins PfBDP1 and PfBDP2 that were recently shown to regulate transcription of genes of merozoite invasion [37]. Alternatively, these may involve other unique Plasmodium genes that were proposed to also function as chromatin readers despite of an apparent absence of conserved chromatin binding domains such as Pf14-3-3 that was shown to bind phosphorylated H3 [45].

Clonally variant multigene (CVM) families impart phenotypic diversity to $P$. falciparum, which is essential for its survival and immune evasion. There is ample evidence 
that single active var gene is enriched with H3K9ac and H3K4me3 [23, 25]. The association of H4ac with the active var gene was seen in a ChIP-assay followed by dot blot [46] but has never been confirmed in a more systematic way. In addition, PfMYST, the $P$. falciparum histone acetyl transferase, which acetylates histone $\mathrm{H} 4$ at $\mathrm{K} 5,8$, 12 and 16, occupies active var promoter [47]. We demonstrate that H4K8 acetylation, apart from euchromatin, is another putative component of the heterochromatin environment, showing over-enrichment at the upstream region of the dominant var gene along with H3K9ac. In one of the studies, clonally variant multigene family genes showed a similar occupancy profile across the IDC to ring stage genes for all histone marks (including H3K9ac) except H4ac and H3Kme3 serving as the activation and repressive marks, respectively, at CVM genes [22]. This shows that association of H3K9ac and H4K8ac at the var genes or other clonally variant multigene family genes might have distinct roles. While both H3K9ac and $\mathrm{H} 4 \mathrm{~K} 8 \mathrm{ac}$ are required for the mutually exclusive expression of dominant members, $\mathrm{H} 4 \mathrm{~K} 8 \mathrm{ac}$ is required to overall regulate the expression of CVM genes.

The most significant observation made by our study is the inverse transcriptional relationship between the proliferation genes and genes of host-parasite interaction governed by H4ac4 and H4K8ac, specifically. The increased MR in case of H4K8R and H4ac4R mutants supports the model of H4K8ac playing the role of main regulator in this process. The enhanced MR is likely a reflection of the increased number of invasive merozoites and/or their viability, presumably boosted by the upregulation of the proliferation-linked genes. This observation tempts us to speculate that the Plasmodium cells have the ability to regulate their growth and (inversely) antigenic presentation both of which is controlled epigenetically. This is consistent with a previously conceived model in which the asexually growing Plasmodium parasite is in a rapidly proliferating cellular state [48], which upon casual triggering undergoes a cascade of events leading to developmental stage transitions. These triggers include several factors of physiologic environment to which the parasite can respond in its natural conditions within human host [1]. All these factors were previously shown to trigger epigenetic factors of gene expression presumably affecting the parasite physiology as a response. In 2 of our previous studies, artemisinin-resistant parasites were marked by overexpression of genes belonging to ribosome assembly and maturation $[49,50]$. Upregulation of invasion-related rhoptry and merozoite surface proteins is seen during reduced expression of multidrug resistant genes Pfcrt and Pfmdr1 [51]. As such, the reduced expression of these genes during $\mathrm{H} 4$ hypoacetylation might be mimicking a putative resistant mechanism leading to better survival of the parasites. HDAC inhibitor-induced H4K8ac hyperacetylation is also mimicked when the cells are treated with artemisinin [40]. In light of these results, it will be interesting to investigate the potential role of H4K8ac in parasite's adaptation to its natural host during both individual- and population-level infections.

Targeting chromatin remodeling and mechanisms of epigenetic regulation of transcription is believed to have a high potential for development of new malaria intervention strategies. TSA and other HDAC inhibitors have been previously evaluated as anti-malaria drugs due to their promising activity and selectivity seen in vitro and in vivo against Plasmodium parasites [52]. In accordance with the role of H4K8ac to be the major hallmark of regulation among the other histone $\mathrm{H} 4$ modifications, it was also found to be the most responsive modification to HDAC inhibitors in P. falciparum. The transient hyperacetylation was copied in expression as well as H4K8 binding to DNA. The return of hyperacetylation to pretreatment conditions after drug removal supports the notion that these drugs are fast metabolized in the cell followed by decrease in their effective concentration [53], indicating the reversible effect to be a more general property of HDAC inhibitors. However, the irreversible effect on some histone acetylations tempts us to speculate that these two types of events are mediated by distinct histone modifications potentially generated by two distinct HDAC enzymes: PfHDAC1 for the reversible changes of euchromatin $[44,54]$ and the PfHDA2 for the irreversible changes involved in the gametocyte conversion [55]. Our hypothesis is supported by the fact that the small number of genes that remained de-repressed even after TSA removal belonged to gametocyte and merozoite stages. Our results confirm the role of histone modifications in exo-erythrocytic stages, and HDAC inhibitors have shown to cause hyperacetylation of $P$. falciparum gametocyte histone proteins [56]. Overall, our study opens avenue to explore HDAC inhibitors and other compound which target histone acetylations especially $\mathrm{H} 4 \mathrm{~K} 8 \mathrm{ac}$ for developing novel drugs against multiple stages of malaria parasites.

\section{Conclusions}

Plasmodium falciparum exhibits unique molecular mechanisms controlling chromatin remodeling as well as mechanisms that link epigenetic markers with transcription. Targeting of these molecular mechanisms has a high potential for development of new malaria intervention strategies. With our efforts to look at the combinatorial effects of histone marks on expression patterns, we can hope to decipher the histone code underlying complex regulatory make-up of these parasites and identify important elements of disease development. Our studies demonstrate 
the unique role of $\mathrm{H} 4 \mathrm{~K} 8 \mathrm{ac}$ in maintaining the chromatin environment in $P$. falciparum. A threshold level of this acetylation most likely is required to keep the euchromatin or heterochromatin in a transcriptionally active state.

\section{Methods}

Parasite culture and drug treatments

P. falciparum strain 3D7 cells were cultured and synchronized under standard conditions [57]. Parasitemia was determined either by microscopic counting or cell sorting in the flow cytometer LSR Fortessa X-20 (BD Biosciences) using Hoechst 33342 (Sigma) [58].

\section{Drug treatments}

Plasmodium falciparum cells were treated with $\mathrm{IC}_{90}$ values of apicidin $(70 \mathrm{nM})$ or TSA $(50 \mathrm{nM})$ at $5 \%$ parasitemia and $2 \%$ hematocrit for $6 \mathrm{~h}$ at 20-24 hpi. DMSO was used as a vehicle control. For wash-off experiments, drug-treated cells were pelleted down and washed with RPMI at least twice before culturing in fresh media without drug for specified time intervals and subsequently harvested for protein extraction, RNA extraction or chromatin immunoprecipitation. All experiments were done in either duplicates or triplicates.

\section{Plasmid construction and transfection}

Histone $\mathrm{H} 4$ gene was mutated such that the targeted lysine $(\mathrm{K})$ residues $(\mathrm{K} 5, \mathrm{~K} 8, \mathrm{~K} 12, \mathrm{~K} 16)$ were replaced with arginine (R). These amino acid exchanges were previously shown to preserve the positive charge but prevent acetylation [59, 60]. For this, plasmid pBCamR-3HA [35] was modified to create HA-tagged version of wild-type or mutated histone $\mathrm{H} 4$ gene in all constructs. Mutations in $\mathrm{H} 4$ gene were introduced by amplifying complete $\mathrm{H} 4$ gene of $P$. falciparum using forward primer carrying the respective change in nucleotide sequence (see Additional file 1). Unmodified $\mathrm{H} 4$ or $\mathrm{H} 4$ carrying mutations were cloned upstream of $3 \mathrm{HA}$ at Bam H1/Nhe 1 sites of $\mathrm{pBcamR}-3 \mathrm{HA}$ to make a fusion with the 3HA tag epitope and transfected into $P$. falciparum using the blasticidindriven regulatable transgene expression systems [61]. Plasmodium falciparum strain 3D7 was transfected as described [62] to carry episomal copies of the plasmids in presence of selection marker blasticidin. Once the transfectants were stably maintained, the concentration of blasticidin was increased from 2.5 to $10 \mu \mathrm{g} / \mathrm{ml}$ in a dominant-negative selection system, which allowed the dominant expression of HA-tagged H4 protein.

\section{Protein extraction and immunodetection}

For total protein, parasitized RBCs were lysed with $0.1 \%$ saponin and washed 2-3 times with PBS. Parasite pellets were resuspended in Laemmli SDS sample buffer, incubated at $100{ }^{\circ} \mathrm{C}$ for $10 \mathrm{~min}$ and centrifuged at maximum speed for 10 min to recover the supernatant.

Nuclear fractionation was done as described [35]. Briefly, saponin-lysed parasite pellets were incubated in cell lysis buffer CLB (20 mM HEPES (pH7.9), $10 \mathrm{mM}$ $\mathrm{KCl}, 1 \mathrm{mM}$ EDTA, $1 \mathrm{mM}$ EGTA, 0.65\% NP-40, $1 \mathrm{mM}$ DTT, protease inhibitors (Complete TM, Roche Diagnostics)) for $5 \mathrm{~min}$ on ice. Nuclei were pelleted at $5000 \mathrm{rpm}$, washed twice with CLB and digested with 300U MNase (Fermentas) in digestion buffer DB $(20 \mathrm{mM}$ Tris- $\mathrm{HCl}$, pH7.5, $15 \mathrm{mM} \mathrm{NaCl}, 60 \mathrm{mM} \mathrm{KCl}, 1 \mathrm{mM} \mathrm{CaCl} 2,5 \mathrm{mM}$ $\mathrm{MgCl} 2,5 \mathrm{mM} \mathrm{MnCl} 2,300 \mathrm{mM}$ sucrose, $0.4 \% \mathrm{NP}-40$, $1 \mathrm{mM}$ DTT, protease inhibitors) for $20 \mathrm{~min}$ at $37{ }^{\circ} \mathrm{C}$. Soluble low salt nuclear fractions were recovered by centrifugation for $10 \mathrm{~min}$ at 13,000 rpm. Remaining nuclear debris was washed twice in DB and resuspended in high salt buffer HSB (20 mM HEPES (pH 7.9), $800 \mathrm{mM} \mathrm{KCl,}$ $1 \mathrm{mM}$ EDTA, $1 \mathrm{mM}$ EGTA, $1 \mathrm{mM}$ DTT, protease inhibitors) by vortexing for $20 \mathrm{~min}$ at $4{ }^{\circ} \mathrm{C}$. High salt nuclear fraction was recovered; after centrifugation for $5 \mathrm{~min}$ at $13,000 \mathrm{rpm}$, the high salt nuclear fraction was saved. The insoluble pellet was solubilized in SDS extraction buffer [2\%SDS, $10 \mathrm{mM}$ Tris- $\mathrm{HCl}(\mathrm{pH} 7.5)]$ by vortexing for $20 \mathrm{~min}$ at room temperature.

Acid extraction of histones was modified from the original protocol [63]. Briefly, the insoluble nuclear pellet containing DNA and histones was treated overnight with $0.25 \mathrm{M} \mathrm{HCl}$ at $4{ }^{\circ} \mathrm{C}$. The acid-extractable protein was precipitated with trichloroacetic acid (TCA), washed in icecold acetone, and resuspended in Laemmli sample buffer.

For immunoblotting, identical amount of total protein lysates separated by $12 \%$ SDS-PAGE were transferred onto nitrocellulose membrane. Western blot analyses were carried out using primary antibodies probed against the core histone modifications (or HA from Sigma) obtained from Millipore, Upstate and horseradish peroxidase-conjugated secondary antibody from GE Healthcare. Polyclonal PfHDAC1 anti-serum [39], and actin (Millipore) were used as loading controls. Enhanced chemiluminescence kit was used for detection according to manufacturer's instructions (Santa Cruz biotechnology, INC).

Immunofluorescence was carried out as described [64] using primary antibodies against HA (1:200) or H4K8ac (1:1000) and fluorophore-conjugated secondary antibodies (Invitrogen). Slides were visualized under Carl Zeiss LSM 510 Confocal Laser Scanning

Microscope.

\section{RNA preparation}

Parasitized RBC pellets containing synchronized parasites from different stages were harvested and stored at $-80{ }^{\circ} \mathrm{C}$. RNA extraction, cDNA synthesis and 
amplification of cDNA were carried out as illustrated [65].

\section{Chromatin immunoprecipitation}

Formaldehyde cross-linked chromatin was sonicated for 8 cycles or 20 cycles in case of ChIP-on-chip or ChIPSeq, respectively, and immunoprecipitated as described [21].

\section{Microarray hybridizations and data analysis Hybridization}

Random amplification of immunoprecipitated DNA as well as input DNA for microarray was carried out for 30 cycles as described [65]. Equal amounts of Cy5 and Cy3 labeled ChIP and input DNA, respectively, were hybridized on P. falciparum custom arrays containing 5402 50-mer intergenic oligonucleotide probes and 10,416 70-mer ORF probes representing 5343 coding genes [66]. For RNA analysis, cDNA labeled with Cy5 was mixed with equal amounts of Cy3-labeled cDNA made from RNA from 3D7 parasites of all stages. The hybridizations were done on arrays containing P. falciparum ORF probes only. All hybridizations were performed on the Agilent hybridization system, and microarray scanning was done using Power Scanner (Tecan, Austria). Data were acquired using GenePix Prov6.0 software (Axon Instruments, USA).

\section{Data analysis}

The microarray data were normalized using the Limma package of $\mathrm{R}$ [67]. Briefly, LOWESS normalization was applied to all spots on each array followed by quantile normalization between arrays. Spots with flags $>0$ and median foreground intensity $>1.5$-fold median background intensity for either channel were included. The normalized $\log 2$ ratio of Cy 5 versus Cy 3 channel was used to present the fold change. The gene expression ratio was calculated by averaging the ratios for all probes mapping to the ORF of a gene.

Functional analyses were carried out to calculate functionally enriched pathways in a given dataset (using the functional gene annotation by MPMP [68]). Over-representation of pathways as compared to their respective frequency in the genome was calculated based on hypergeometric test $(P<0.05)$.

\section{Quantitative real-time PCR}

For ChIP validation, qPCR was carried out on immunoprecipitated and input DNA samples. ChIP enrichment was calculated by using the $\Delta \mathrm{Ct}$ method (Ct of immunoprecipitated target gene-Ct of input target gene) where $\mathrm{Ct}$ is the threshold cycle. All PCRs were done in duplicates or triplicates. Validation of invasion and proliferation genes was done by reverse transcribing RNA from $\mathrm{H} 4-\mathrm{HA}$ and $\mathrm{H} 4 \mathrm{~K} 8 \mathrm{R}$ parasites (rings, trophozoites and schizonts) into cDNA. All qPCRs were performed using either Applied Biosystems SYBR Select Mix or SYBR Green PCR Master Mix (Bio-Rad) according to the manufacturer's instructions.

\section{High-throughput ChIP-Seq Library preparation}

Purified DNA from H4K8ac immunoprecipitated chromatin of ring, trophozoite and schizont stages as well as sonicated genomic input DNA (schizont stage input DNA) was used to prepare ChIP-Seq libraries. Libraries for ChIP-Seq were prepared using NEBNext Ultra DNA library prep kit from Illumina according to manufacturer's instructions with a few modifications in amplification. Libraries were amplified for 3 PCR cycles $(15 \mathrm{~s}$ at $98{ }^{\circ} \mathrm{C}, 30 \mathrm{~s}$ at $55^{\circ} \mathrm{C}, 30 \mathrm{~s}$ at $\left.62{ }^{\circ} \mathrm{C}\right)$ followed by $7-9$ PCR cycles $\left(15 \mathrm{~s}\right.$ at $98{ }^{\circ} \mathrm{C}, 30 \mathrm{~s}$ at $63{ }^{\circ} \mathrm{C}, 30 \mathrm{~s}$ at $\left.65^{\circ} \mathrm{C}\right)$ using KAPA HiFi HotStart Ready Mix (Kapa Biosystems, Woburn, MA). 150-bp paired end reads were obtained using HiSeq 2500 (Illumina).

\section{Data processing}

Sequence reads were aligned to the $P$. falciparum genome (downloaded from Gene DB, Jul2015) using BWA, version 0.7.12 [69]. After adapter trimming using skewer version, 0.1.125 [70], and removal of PCR duplicates, uniquely aligned reads (mapping quality $>20$, the probability of incorrect mapping $<0.01$ ) were extracted out for further study.

\section{Data visualization}

The processed data were visualized using integrative genomics viewer (IGV) interface [71]. ChIP-Seq profiles for gene models were generated using total reads counts. For this, total read coverage at 50-bp intervals was determined for regions spanning $1 \mathrm{~kb}$ upstream of start codon and $1 \mathrm{~kb}$ downstream of stop codon. Read coverage within ORF was calculated in 30 bins with the interval size approximate to $50 \mathrm{bp}$ (the average length of genes in the whole genome is $1500 \mathrm{bp}$ ). Finally, for every library, the read coverage of each bin was normalized by the corresponding read coverage of that bin in the control input library.

\section{Peak calling}

The enrichment of histone occupancies was determined by peak calling algorithm built in MACS, version 2.1 [72] applied with parameters-nomodel- $q 0.25$-broad-slocal 500 . 


\section{Additional files}

Additional file 1. (a) Vector map (b) ChIP-Seq coverage (c) Primer sequences used in this study (d) Supplemental figure and table legends.

Additional file 2: Figure S1. P. falciparum transgenic lines for mutations in $\mathrm{H} 4$ acetylations (related to Fig. 1).

Additional file 3: Table S1. Genes differentially expressed in the transfectants (related to Fig. 1).

Additional file 4. Figure S2. Differentially expressed pathways in the transfectants (related to Fig. 1).

Additional file 5. Table S5. Parasite age estimation from RNA expression data of the transfectants (related to Fig. 1).

Additional file 6. Table S2. Genes that remain deregulated after removal of TSA (related to Fig. 2).

Additional file 7. Table S3. Overlap between H4K8ac binding and expression changes during TSA treatment (related to Fig. 2).

Additional file 8. Figure $\mathbf{S 3}$. Histone marks at dominant var genes (related to Fig. 3).

Additional file 9. Figure S4. ChIP coupled to high throughput sequencing (related to Fig. 4).

Additional file 10. Table S4. MACS identified peaks for H4K8ac ChIP-Seq (related to Fig. 4)

\section{Abbreviations}

ac: acetylation; me: methylation; IDC: intraerythrocytic developmental cycle: PTM: post transcriptional modification; ORF: open reading frame; IGR: intergenic region; HDAC: histone deacetylase inhibitor; TSA: trichostatin A; ChIP: chromatin immunoprecipitation; bp: base pair.

\section{Authors' contributions}

APG and ZB conceived and designed the experiments and wrote the manuscript. APG, JT, MK and AP performed the experiments. APG and $L Z$ analyzed the data. All authors read and approved the final manuscript.

\section{Acknowledgements}

The authors are thankful to Dr. Sachel Mok for providing 3D7 clones, Prof. Till Voss for sharing pBCamR-3HA plasmid and Chin Wai Ho for technical assistance.

\section{Competing interests}

The authors declare that they have no competing interests.

\section{Availability of data and materials}

The microarray data (Accession Number GSE84084) and ChIP-Seq data (Accession Number GSE93145) from this study have been deposited into NCBI GEO.

\section{Consent for publication}

Not applicable.

\section{Ethics approval and consent to participate}

Not applicable.

\section{Funding}

This work is funded by the Tier 2 grant of the Ministry of Education Singapore; Grant Number MOE2013-T2-1-055.

\section{Publisher's Note}

Springer Nature remains neutral with regard to jurisdictional claims in published maps and institutional affiliations.

Received: 29 March 2017 Accepted: 7 August 2017

Published online: 22 August 2017
References

1. Merrick CJ, Duraisingh MT. Epigenetics in Plasmodium: what do we really know? Eukaryot Cell. 2010;9:1150-8.

2. Ay F, Bunnik EM, Varoquaux N, Vert JP, Noble WS, Le Roch KG. Multiple dimensions of epigenetic gene regulation in the malaria parasite Plasmodium falciparum: gene regulation via histone modifications, nucleosome positioning and nuclear architecture in P. falciparum. BioEssays. 2015;37:182-94.

3. Cui L, Miao J. Chromatin-mediated epigenetic regulation in the malaria parasite Plasmodium falciparum. Eukaryot Cell. 2010;9(8):1137-49.

4. Duffy MF, Selvarajah SA, Josling GA, Petter M. Epigenetic regulation of the Plasmodium falciparum genome. Brief Funct Genomics. 2014;13:203-16.

5. Hoeijmakers WA, Stunnenberg HG, Bartfai R. Placing the Plasmodium falciparum epigenome on the map. Trends Parasitol. 2012;28:486-95.

6. Salcedo-Amaya AM, Hoeijmakers WA, Bartfai R, Stunnenberg HG. Malaria: could its unusual epigenome be the weak spot? Int J Biochem Cell Biol. 2010;42:781-4.

7. Voss TS, Bozdech Z, Bartfai R. Epigenetic memory takes center stage in the survival strategy of malaria parasites. Curr Opin Microbiol. 2014;20:88-95.

8. Batugedara G, Lu XM, Bunnik EM, Le Roch KG. The role of chromatin structure in gene regulation of the human malaria parasite. Trends Parasitol. 2017;33:364-77.

9. Kirchner S, Power BJ, Waters AP. Recent advances in malaria genomics and epigenomics. Genome Med. 2016;8:92.

10. Gupta AP, Bozdech Z. Epigenetic landscapes underlining global patterns of gene expression in the human malaria parasite, Plasmodium falciparum. Int J Parasitol. 2017;47(7):399-407.

11. Miao J, Fan Q, Cui L, Li J. The malaria parasite Plasmodium falciparum histones: organization, expression, and acetylation. Gene. 2006;369:53-65.

12. Coulson RM, Hall N, Ouzounis CA. Comparative genomics of transcriptional control in the human malaria parasite Plasmodium falciparum. Genome Res. 2004;14:1548-54.

13. Baum J, Papenfuss AT, Mair GR, Janse CJ, Vlachou D, Waters AP, Cowman AF, Crabb BS, de Koning-Ward TF. Molecular genetics and comparative genomics reveal RNAi is not functional in malaria parasites. Nucleic Acids Res. 2009;37:3788-98.

14. Lopez-Rubio JJ, Mancio-Silva L, Scherf A. Genome-wide analysis of heterochromatin associates clonally variant gene regulation with perinuclear repressive centers in malaria parasites. Cell Host Microbe. 2009;5:179-90.

15. Salcedo-Amaya AM, van Driel MA, Alako BT, Trelle MB, van den Elzen AM, Cohen AM, Janssen-Megens EM, van de Vegte-Bolmer M, Selzer RR, Iniguez AL, et al. Dynamic histone $\mathrm{H} 3$ epigenome marking during the intraerythrocytic cycle of Plasmodium falciparum. Proc Natl Acad Sci USA. 2009;106:9655-60.

16. Lemieux JE, Kyes SA, Otto TD, Feller Al, Eastman RT, Pinches RA, Berriman M, Su XZ, Newbold Cl. Genome-wide profiling of chromosome interactions in Plasmodium falciparum characterizes nuclear architecture and reconfigurations associated with antigenic variation. Mol Microbiol. 2013;90:519-37.

17. Trelle MB, Salcedo-Amaya AM, Cohen AM, Stunnenberg HG, Jensen ON Global histone analysis by mass spectrometry reveals a high content of acetylated lysine residues in the malaria parasite Plasmodium falciparum. J Proteome Res. 2009:8:3439-50.

18. Saraf A, Cervantes S, Bunnik EM, Ponts N, Sardiu ME, Chung DW, Prudhomme J, Varberg JM, Wen Z, Washburn MP, et al. Dynamic and combinatorial landscape of histone modifications during the intraerythrocytic developmental cycle of the malaria parasite. J Proteome Res. 2016;15:2787-801.

19. Coetzee N, Sidoli S, van Biljon R, Painter H, Llinas M, Garcia BA, Birkholtz LM. Quantitative chromatin proteomics reveals a dynamic histone posttranslational modification landscape that defines asexual and sexual Plasmodium falciparum parasites. Sci Rep. 2017;7:607.

20. Bartfai R, Hoeijmakers WA, Salcedo-Amaya AM, Smits AH, JanssenMegens E, Kaan A, Treeck M, Gilberger TW, Francoijs KJ, Stunnenberg HG. H2A.Z demarcates intergenic regions of the Plasmodium falciparum epigenome that are dynamically marked by H3K9ac and H3K4me3. PLoS Pathog. 2010;6:e1001223.

21. Gupta AP, Chin WH, Zhu L, Mok S, Luah YH, Lim EH, Bozdech Z. Dynamic epigenetic regulation of gene expression during the life cycle of malaria parasite Plasmodium falciparum. PLoS Pathog. 2013;9:e1003170. 
22. Karmodiya K, Pradhan SJ, Joshi B, Jangid R, Reddy PC, Galande S. A comprehensive epigenome map of Plasmodium falciparum reveals unique mechanisms of transcriptional regulation and identifies H3K36me2 as a global mark of gene suppression. Epigenet Chromatin. 2015:8:32.

23. Petter M, Lee CC, Byrne TJ, Boysen KE, Volz J, Ralph SA, Cowman AF, Brown GV, Duffy MF. Expression of P. falciparum var genes involves exchange of the histone variant H2A.Z at the promoter. PLoS Pathog. 2011;7:e1001292.

24. Jiang L, Mu J, Zhang Q, Ni T, Srinivasan P, Rayavara K, Yang W, Turner $L$, Lavstsen T, Theander TG, et al. PfSETvs methylation of histone H3K36 represses virulence genes in Plasmodium falciparum. Nature. 2013:499:223-7.

25. Lopez-Rubio JJ, Gontijo AM, Nunes MC, Issar N, Hernandez Rivas R, Scherf A. $5^{\prime}$ Flanking region of var genes nucleate histone modification patterns linked to phenotypic inheritance of virulence traits in malaria parasites. Mol Microbiol. 2007;66:1296-305.

26. Hoeijmakers WA, Flueck C, Francoijs KJ, Smits AH, Wetzel J, Volz JC, Cowman AF, Voss T, Stunnenberg HG, Bartfai R. Plasmodium falciparum centromeres display a unique epigenetic makeup and cluster prior to and during schizogony. Cell Microbiol. 2012;14:1391-401.

27. Petter M, Selvarajah SA, Lee CC, Chin WH, Gupta AP, Bozdech Z, Brown GV, Duffy MF. H2A.Z and H2B.Z double-variant nucleosomes define intergenic regions and dynamically occupy var gene promoters in the malaria parasite Plasmodium falciparum. Mol Microbiol. 2013;87(6):1167-82.

28. Fraschka SA, Henderson RW, Bartfai R. H3.3 demarcates GC-rich coding and subtelomeric regions and serves as potential memory mark for virulence gene expression in Plasmodium falciparum. Sci Rep. 2016;6:31965.

29. Bunnik EM, Polishko A, Prudhomme J, Ponts N, Gill SS, Lonardi S, Le Roch KG. DNA-encoded nucleosome occupancy is associated with transcription levels in the human malaria parasite Plasmodium falciparum. BMC Genomics. 2014;15:347.

30. Kensche PR, Hoeijmakers WA, Toenhake CG, Bras M, Chappell L, Berriman M, Bartfai R. The nucleosome landscape of Plasmodium falciparum reveals chromatin architecture and dynamics of regulatory sequences. Nucleic Acids Res. 2016;44:2110-24.

31. Westenberger SJ, Cui L, Dharia N, Winzeler E. Genome-wide nucleosome mapping of Plasmodium falciparum reveals histone-rich coding and histone-poor intergenic regions and chromatin remodeling of core and subtelomeric genes. BMC Genomics. 2009;10:610.

32. Ponts N, Harris EY, Prudhomme J, Wick I, Eckhardt-Ludka C, Hicks GR, Hardiman G, Lonardi S, Le Roch KG. Nucleosome landscape and control of transcription in the human malaria parasite. Genome Res. 2010;20:228-38

33. Ponts N, Harris EY, Lonardi S, Le Roch KG. Nucleosome occupancy at transcription start sites in the human malaria parasite: a hard-wired evolution of virulence? Infect Genet Evol. 2011;11:716-24.

34. Brancucci NM, Bertschi NL, Zhu L, Niederwieser I, Chin WH, Wampfler R, Freymond C, Rottmann M, Felger I, Bozdech Z, Voss TS. Heterochromatin protein 1 secures survival and transmission of malaria parasites. Cell Host Microbe. 2014;16:165-76.

35. Flueck C, Bartfai R, Volz J, Niederwieser I, Salcedo-Amaya AM, Alako BT, Ehlgen F, Ralph SA, Cowman AF, Bozdech Z, et al. Plasmodium falciparum heterochromatin protein 1 marks genomic loci linked to phenotypic variation of exported virulence factors. PLoS Pathog. 2009;5:e1000569.

36. Perez-Toledo K, Rojas-Meza AP, Mancio-Silva L, Hernandez-Cuevas NA Delgadillo DM, Vargas M, Martinez-Calvillo S, Scherf A, Hernandez-Rivas R. Plasmodium falciparum heterochromatin protein 1 binds to tri-methylated histone 3 lysine 9 and is linked to mutually exclusive expression of var genes. Nucleic Acids Res. 2009;37:2596-606.

37. Josling GA, Petter M, Oehring SC, Gupta AP, Dietz O, Wilson DW, Schubert T, Langst G, Gilson PR, Crabb BS, et al. A Plasmodium falciparum bromodomain protein regulates invasion gene expression. Cell Host Microbe. 2015;17:741-51.

38. Rai R, Zhu L, Chen H, Gupta AP, Sze SK, Zheng J, Ruedl C, Bozdech Z, Featherstone M. Genome-wide analysis in Plasmodium falciparum reveals early and late phases of RNA polymerase II occupancy during the infectious cycle. BMC Genomics. 2014;15:959.

39. Chaal BK, Gupta AP, Wastuwidyaningtyas BD, Luah YH, Bozdech Z. Histone deacetylases play a major role in the transcriptional regulation of the Plasmodium falciparum life cycle. PLoS Pathog. 2010;6:e1000737.
40. Gupta DK, Patra AT, Zhu L, Gupta AP, Bozdech Z. DNA damage regulation and its role in drug-related phenotypes in the malaria parasites. Sci Rep. 2016;6:23603

41. Wang Z, Zang C, Rosenfeld JA, Schones DE, Barski A, Cuddapah S, Cui K, Roh TY, Peng W, Zhang MQ, Zhao K. Combinatorial patterns of histone acetylations and methylations in the human genome. Nat Genet. 2008:40:897-903.

42. Magraner-Pardo L, Pelechano V, Coloma MD, Tordera V. Dynamic remodeling of histone modifications in response to osmotic stress in Saccharomyces cerevisiae. BMC Genomics. 2014;15:247.

43. Bozdech Z, Llinas M, Pulliam BL, Wong ED, Zhu J, DeRisi JL. The transcriptome of the intraerythrocytic developmental cycle of Plasmodium falciparum. PLoS Biol. 2003;1:E5

44. Andrews KT, Gupta AP, Tran TN, Fairlie DP, Gobert GN, Bozdech Z. Comparative gene expression profiling of $P$. falciparum malaria parasites exposed to three different histone deacetylase inhibitors. PLoS ONE. 2012;7:e31847.

45. Dastidar EG, Dzeyk K, Krijgsveld J, Malmquist NA, Doerig C, Scherf A, Lopez-Rubio JJ. Comprehensive histone phosphorylation analysis and identification of Pf14-3-3 protein as a histone $\mathrm{H} 3$ phosphorylation reader in malaria parasites. PLoS ONE. 2013;8:e53179.

46. Freitas-Junior LH, Hernandez-Rivas R, Ralph SA, Montiel-Condado D, Ruvalcaba-Salazar OK, Rojas-Meza AP, Mancio-Silva L, Leal-Silvestre RJ, Gontijo AM, Shorte S, Scherf A. Telomeric heterochromatin propagation and histone acetylation control mutually exclusive expression of antigenic variation genes in malaria parasites. Cell. 2005;121:25-36.

47. Miao J, Fan Q, Cui L, Li X, Wang H, Ning G, Reese JC, Cui L. The MYST family histone acetyltransferase regulates gene expression and cell cycle in malaria parasite Plasmodium falciparum. Mol Microbiol. 2010;78:883-902.

48. Salcedo-Sora JE, Caamano-Gutierrez E, Ward SA, Biagini GA. The proliferating cell hypothesis: a metabolic framework for Plasmodium growth and development. Trends Parasitol. 2014;30:170-5.

49. Mok S, Imwong M, Mackinnon MJ, Sim J, Ramadoss R, Yi P, Mayxay $\mathrm{M}$, Chotivanich K, Liong KY, Russell B, et al. Artemisinin resistance in Plasmodium falciparum is associated with an altered temporal pattern of transcription. BMC Genomics. 2011;12:391.

50. Mok S, Ashley EA, Ferreira PE, Zhu L, Lin Z, Yeo T, Chotivanich K, Imwong M, Pukrittayakamee S, Dhorda M, et al. Drug resistance. Population transcriptomics of human malaria parasites reveals the mechanism of artemisinin resistance. Science. 2015;347:431-5.

51. Adjalley SH, Scanfeld D, Kozlowski E, Llinas M, Fidock DA. Genome-wide transcriptome profiling reveals functional networks involving the Plasmodium falciparum drug resistance transporters PFCRT and PFMDR1. BMC Genomics. 1090;2015:16.

52. Andrews KT, Tran TN, Fairlie DP. Towards histone deacetylase inhibitors as new antimalarial drugs. Curr Pharm Des. 2012;18(24):3467-79.

53. Waterborg JH. Plant histone acetylation: in the beginning. Biochim Biophys Acta. 2011;1809:353-9.

54. Patel V, Mazitschek R, Coleman B, Nguyen C, Urgaonkar S, Cortese J, Barker RH, Greenberg E, Tang W, Bradner JE, et al. Identification and characterization of small molecule inhibitors of a class I histone deacetylase from Plasmodium falciparum. J Med Chem. 2009;52:2185-7.

55. Coleman BI, Skillman KM, Jiang RH, Childs LM, Altenhofen LM, Ganter M, Leung Y, Goldowitz I, Kafsack BF, Marti M, et al. A Plasmodium falciparum histone deacetylase regulates antigenic variation and gametocyte conversion. Cell Host Microbe. 2014;16:177-86.

56. Trenholme K, Marek L, Duffy S, Pradel G, Fisher G, Hansen FK, SkinnerAdams TS, Butterworth A, Ngwa CJ, Moecking J, et al. Lysine acetylation in sexual stage malaria parasites is a target for antimalarial small molecules. Antimicrob Agents Chemother. 2014;58:3666-78.

57. Trager W, Jensen JB. Human malaria parasites in continuous culture. 1976. J Parasitol. 2005;91:484-6.

58. Malleret B, Claser C, Ong AS, Suwanarusk R, Sriprawat K, Howland SW, Russell B, Nosten F, Renia L. A rapid and robust tri-color flow cytometry assay for monitoring malaria parasite development. Sci Rep. 2011;1:118.

59. Zhang W, Bone JR, Edmondson DG, Turner BM, Roth SY. Essential and redundant functions of histone acetylation revealed by mutation of target lysines and loss of the Gcn5p acetyltransferase. EMBO J. 1998:17:3155-67. 
60. Dion MF, Altschuler SJ, Wu LF, Rando OJ. Genomic characterization reveals a simple histone $\mathrm{H} 4$ acetylation code. Proc Natl Acad Sci USA. 2005;102:5501-6.

61. Epp C, Raskolnikov D, Deitsch KW. A regulatable transgene expression system for cultured Plasmodium falciparum parasites. Malar J. 2008;7:86.

62. Nkrumah LJ, Muhle RA, Moura PA, Ghosh P, Hatfull GF, Jacobs WR Jr, Fidock DA. Efficient site-specific integration in Plasmodium falciparum chromosomes mediated by mycobacteriophage Bxb1 integrase. Nat Methods. 2006;3:615-21.

63. Longhurst HJ, Holder AA. The histones of Plasmodium falciparum: identification, purification and a possible role in the pathology of malaria. Parasitology. 1997; 114(Pt 5):413-9.

64. Luah YH, Chaal BK, Ong EZ, Bozdech Z. A moonlighting function of Plasmodium falciparum histone 3, mono-methylated at lysine 9? PLoS ONE. 2010;5:e10252.

65. Bozdech Z, Mok S, Gupta AP. DNA microarray-based genome-wide analyses of Plasmodium parasites. Methods Mol Biol. 2013;923:189-211.
66. Hu G, Llinas M, Li J, Preiser PR, Bozdech Z. Selection of long oligonucleotides for gene expression microarrays using weighted rank-sum strategy. BMC Bioinform. 2007;8:350.

67. Edwards D. Non-linear normalization and background correction in onechannel cDNA microarray studies. Bioinformatics. 2003;19:825-33.

68. Ginsburg H. Progress in in silico functional genomics: the malaria metabolic pathways database. Trends Parasitol. 2006;22:238-40.

69. Li H. Exploring single-sample SNP and INDEL calling with whole-genome de novo assembly. Bioinformatics. 2012;28:1838-44.

70. Jiang H, Lei R, Ding SW, Zhu S. Skewer: a fast and accurate adapter trimmer for next-generation sequencing paired-end reads. BMC Bioinform. 2014;15:182.

71. Robinson JT, Thorvaldsdottir H, Winckler W, Guttman M, Lander ES, Getz G, Mesirov JP. Integrative genomics viewer. Nat Biotechnol. 2011;29:24-6.

72. Zhang Y, Liu T, Meyer CA, Eeckhoute J, Johnson DS, Bernstein BE, Nusbaum C, Myers RM, Brown M, Li W, Liu XS. Model-based analysis of ChIP-Seq (MACS). Genome Biol. 2008;9:R137.

\section{Submit your next manuscript to BioMed Central and we will help you at every step:}

- We accept pre-submission inquiries

- Our selector tool helps you to find the most relevant journal

- We provide round the clock customer support

- Convenient online submission

- Thorough peer review

- Inclusion in PubMed and all major indexing services

- Maximum visibility for your research

Submit your manuscript at www.biomedcentral com/submit 